\title{
Influencing Factors and Predictors of Early Response in Schizophrenia Patients Receiving the Paliperidone Extended-Release Tablets (Paliperidone ER)
}

\author{
Seung-Ho Jung ${ }^{1}$, Jin-Sang Yoon ${ }^{2}$, Yong-Min Ahn ${ }^{3}$, Yong-Sik Kim, and Chul-Eung Kim ${ }^{1 凶}$ \\ ${ }^{1}$ Department of Psychiatry, Inha University Hospital, Incheon, Republic of Korea \\ 2Department of Psychiatry, Chonnam National University, Gwangju, Republic of Korea \\ ${ }^{3}$ Department of Psychiatry, Seoul National University Hospital, Seoul, Republic of Korea \\ ${ }^{4}$ Department of Psychiatry, Dongguk University Ilsan Hospital, Goyang, Republic of Korea
}

\begin{abstract}
Objective Paliperidone extended-release tablet (paliperidone ER) is a new oral psychotropic agent developed for schizophrenia treatment. There have been some studies about paliperidone's good efficacy and tolerability. Clinicians appear to change the antipsychotic medication to paliperidone ER. However, it is not known what patients are favorable responsive to paliperidone ER. The aim of this study was to evaluate the characteristics of early responders and investigate predictors of acute response when the medications changed to paliperidone ER.

Methods Data were analyzed from schizophrenic patients who participated in a multi-center, open-label, non-comparative clinical trial. Total 320 patients were examined in this study. Sociodemographic, psychopathology, social function and metabolic data were evaluated. Unpaired t-test for continuous and $\chi^{2}$ for categorical data, respectively, were used to compare early responder and non-responders. Logistic regression analysis was used to establish a prediction model.

Results $38.7 \%$ of study subjects (124 of 320) responded to paliperidone ER treatment. Logistic regression analysis showed that a good paliperidone ER response was more likely when patients were social drinkers, when patients had started medication at inpatient, when negative symptoms were less severe, and when patients' social relationship and self-care were better.

Conclusion Early response to paliperidone ER treatment is associated with less negative symptoms and good social relationships and self-care. Strategies to reduce these symptoms may contribute to early response to paliperidone ER.
\end{abstract}

Psychiatry Investig 2013;10:407-416

Key Words Schizophrenia, Paliperidone ER, Early response, Predictors, Antipsychotics.

\section{INTRODUCTION}

Schizophrenia is chronic and disabling mental illness with serious physical, social, and economic consequences. ${ }^{1,2}$ Today many antipsychotic agents have been developed, and patients experience dramatic symptom improvement in response to currently available antipsychotic treatment. Especially, atypical antipsychotics gave rise to fewer undesirable side effects,

Received: October 24, 2012 Revised: December 27, 2012

Accepted: January 16, 2013 Available online: December 16, 2013

$\triangle$ Correspondence: Chul-Eung Kim, MD, PhD

Department of Psychiatry, Inha University College of Medicine, 27 Inhangro, Jung-gu, Incheon 400-711, Republic of Korea

Tel: +82-32-890-3475, Fax: +82-32-890-3558, E-mail: kce320@inha.ac.kr

(a) This is an Open Access article distributed under the terms of the Creative Commons Attribution Non-Commercial License (http://creativecommons.org/licenses/by$\mathrm{nc} / 3.0$ ) which permits unrestricted non-commercial use, distribution, and reproduction in any medium, provided the original work is properly cited. such as extrapyramidal symptoms (EPS), neuroleptic malignant syndrome (NMS), and tardive dyskinesia (TD). But, although the introduction of the atypical antipsychotic has advanced the treatment of schizophrenia, there is still a need for more efficacious and better therapy tolerated medications. Paliperidone extended release (ER), the major active metabolite of risperidone, is new second-generation antipsychotics. Some randomized controlled studies have suggested the merits of paliperidone ER such as efficacy and tolerability. ${ }^{3-7}$ Also, the controlled delivery profiles of paliperidone ER allows treatment to begin at a potentially therapeutically effective dose without the need for dose titration..$^{8-10}$ Unlike other antipsychotic agents, some studies have suggested that paliperidone does not undergo significant hepatic metabolism, so can be well used by patients with poor hepatic function. ${ }^{11}$ For these advantages, paliperidone ER has been used more frequently 
for treatment of schizophrenia.

Early identification of responders to antipsychotic treatment is important. Today early response is thought to be one of the strongest predictors of subsequent outcome. ${ }^{12-15}$ There has been suggested that an initial response during the first weeks of treatment is a possible predictor of how well patients are going to respond later in treatment. Kinon et al. demonstrated that $84 \%$ of early non-responders at treatment week 2 were subsequent non-responders 3 months later. ${ }^{15}$ Also, Emsley et al. ${ }^{14}$ found that 6 -week treatment response correctly predicted $89 \%$ of remitters and $86 \%$ of non-remitters. Therefore, understanding the factors that influencing the response and predicting the acute response may contribute to optimize treatment strategies during the critical period of the illness. Also, early response identification would prevent unnecessary persistence with ineffective medications and could diminish the risk of adverse events. ${ }^{16}$ Clinicians could identify early non-responder and rapidly switch to a potentially more effective treatment strategy. The duration of hospitalization, illness burden and costs with it could be reduced. ${ }^{17}$ Recently, there has been some studies distinguishing responders in acute phase from non-responders (Table 1). Crespo-Facorro et al. ${ }^{18}$ suggested that patients with an early age of onset, a poor premorbid adolescent functioning, and with a lower severity of psychopathology seem to have a decrease likelihood of responding to antipsy- chotic treatment. Levine et al. reported that patients with a considerable psychopathological improvement during the first two weeks were young, male and patients with paranoid type schizophrenia. ${ }^{19}$ Severe psychopathology at baseline and development of motor side effects at standard antipsychotics doses may indicate a poor early response. ${ }^{20}$

The aims of this analysis was to

1) identify baseline sociodemographic and clinical characteristics of early responders and 2) investigate influencing factors and predictors of early response when switching to paliperidone ER.

\section{METHODS}

The study involved a post huc analysis of two 24-week, multicenter, open-label, non-comparative prospective studies that was originally designed to examine the effectiveness of switching from antipsychotic medication to paliperidone ER in patients with schizophrenia (ClinicalTrials.gov identifier: NCT00761605 and NCT00784238) NCT00761605 PASS (Paliperidone Effectiveness Study to Evaluate the Subjective Symptom Change) study aimed to examine whether the efficacy for subjective symptoms is improved or maintained after switching from the previous oral antipsychotic to paliperidone ER. The primary endpoints were the total score of the symptom

Table 1. Prior studies about predictors of response in acute phase

\begin{tabular}{|c|c|c|c|c|c|}
\hline Study & Population & Study design & Treatments & $\begin{array}{l}\text { Outcome } \\
\text { measure }\end{array}$ & Predictors of response in acute phase \\
\hline $\begin{array}{l}\text { Crespo- } \\
\text { Facorro et al. }{ }^{18}\end{array}$ & $\begin{array}{l}\mathrm{N}=172, \\
\text { first-episode } \\
\text { psychosis }\end{array}$ & $\begin{array}{l}\text { Pooled data } \\
\text { from } \\
\text { epidemiologic } \\
\text { data }\end{array}$ & $\begin{array}{l}\text { Haloperidol, } \\
\text { olanzapine, } \\
\text { risperidone }\end{array}$ & $\begin{array}{c}\text { BPRS } \\
\text { score }\end{array}$ & $\begin{array}{l}\text { The variables were associated with less likelihood } \\
\text { of response in acute phase: lower severity of general } \\
\text { psychopathology, positive symptoms and } \\
\text { disorganized symptoms at baseline, earlier age of } \\
\text { onset, diagnosis of schizophrenia, longer duration of } \\
\text { untreated psychosis, poorer premorbid adjustment } \\
\text { during adolescence, and hospitalization }\end{array}$ \\
\hline Kinon et al. ${ }^{15}$ & $\begin{array}{l}\text { N=1077, } \\
\text { schizophrenia, } \\
\text { schizoaffective, } \\
\text { schizophreniform } \\
\text { disorder }\end{array}$ & $\begin{array}{l}\text { Pooled data } \\
\text { from 5- } \\
\text { randomzed } \\
\text { clinical trials }\end{array}$ & $\begin{array}{l}\text { Olanzapine, } \\
\text { risperidone, } \\
\text { quetiapine, } \\
\text { ziprasidone }\end{array}$ & $\begin{array}{l}\text { PANSS } \\
\text { score }\end{array}$ & $\begin{array}{l}\text { Patients in the early response had shorter illness } \\
\text { duration, higher PANSS Total, Positive and General } \\
\text { Psychopathology scores, were slightly more likely to } \\
\text { be diagnosed with schizoaffective disorder }\end{array}$ \\
\hline $\begin{array}{l}\text { Levine } \\
\text { and Leucht }{ }^{19}\end{array}$ & $\begin{array}{l}\mathrm{N}=538 \\
\text { schizophrenia }\end{array}$ & $\begin{array}{l}\text { Pooled data } \\
\text { from 2- } \\
\text { randomized } \\
\text { clinical trials }\end{array}$ & $\begin{array}{l}\text { Amisulpride, } \\
\text { risperidone }\end{array}$ & $\begin{array}{l}\text { BPRS } \\
\text { score }\end{array}$ & $\begin{array}{l}\text { Patients in the early response were young, male, } \\
\text { suffered from paranoid schizophrenia }\end{array}$ \\
\hline $\begin{array}{l}\text { Schennach } \\
\text { et al. }^{53}\end{array}$ & $\begin{array}{l}\mathrm{N}=112 \text {, } \\
\text { schizophrenia, } \\
\text { schizoaffective, } \\
\text { schizophreniform } \\
\text { disorder }\end{array}$ & $\begin{array}{l}\text { Pooled } \\
\text { data from } \\
\text { naturalistic } \\
\text { multicenter } \\
\text { study }\end{array}$ & $\begin{array}{l}\text { Haloperidol, } \\
\text { risperidone }\end{array}$ & $\begin{array}{l}\text { PANSS } \\
\text { score }\end{array}$ & $\begin{array}{l}\text { Early response and a higher PANSS positive } \\
\text { subscore were identified as predictors of response } \\
\text { in acute phase }\end{array}$ \\
\hline
\end{tabular}

BPRS: Brief Psychiatric Rating Scale, PANSS: Positive and Negative Syndrome Scale 
checking list (SCL-90-R) and secondary endpoints were various variables: Krawiecka scale, CGI-SCH-S, I, PSP, vital Signs, DIEPSS, clinical lab, height, weight, waist circumference. NCT00784238 POWER (Paliperidone Effectiveness Study to Evaluate the Change of Subjective Well-being \& Drug Attitude in Schizophrenic Patients) study aimed to evaluate whether the efficacy for subjective well-being and drug attitude is improved and maintained in patients switched from the previous another antipsychotic to paliperidone ER. The primary outcome of this study was to evaluate whether the efficacy for subjective well-being and drug attitude is improved and maintained in patients. Various variables will be investigated to evaluate responses such as Krawiecka scale, CGI-SCH-S, I, PSP, vital Signs, DIEPSS, clinical Lab, height, weight, waist circumference. There were published articles about these study. ${ }^{21,22}$

The study participants were recruited from 23 study sites in Korea and included patients who were being treated with antipsychotic medication for at least 2 weeks prior to the study screening, and who required a change in antipsychotic medication. The reasons for changing medication were low efficacy, low tolerance, or low compliance. We defined inefficacy was that there was no obviously symptom improvement in 2 weeks with antipsychotic medication. All patients volunteered to participate in these studies, and all provided written informed consent before enrollment.

\section{Subjects}

Patients who met all of the following criteria were eligible for this study

1) Aged between 18 and 65 years.

2) Meeting DSM-IV criteria (Diagnostic and Statistical Manual of Mental Disorder, Fourth Edition, criteria) for a principal diagnosis of schizophrenia.

3) Patients who were moderately ill at baseline defined by the 4 or higher on the CGI-S scale at screening.

4) Patients who were capable of and willing to fill out the questionnaire for themselves.

5) And patients who were compliant with self-medication or were be able to receive consistent help or support.

The exclusion criteria were 1) patients with history of neuroleptic malignant syndrome; 2) patients with known hypersensitivity to risperidone or paliperidone; 3) patients who had been exposed to the study drug or clozapine within 1 month before screening; 4) patients with severe (pathologic or iatrogenic) gastrointestinal stenosis or patients who could not swallow the drug whole; 5) patients with significant risks including suicide or aggressive behavior; 6) patients who had been pregnant or breast feeding at the time of screening interview; 7) patients with significant abnormal findings in biochemical, hematological, or urine analyses, which had been clinically significant at the investigator's discretion; 8) patients who had been treated with long-acting, depot antipsychotics within 28 days of the study; 9) clinician's family or employees of clinical center.

\section{Study design}

During the study period, a flexible dose of paliperidone ER (range: 3-12 mg) was administered daily to all participants. Patients had received mean 2.24 antipsychotic medication trials. Prior antipsychotic medications were risperidone (mean dose; $5.32 \mathrm{mg}$ ), olanzapine (mean dose: $13.83 \mathrm{mg}$ ), quetiapine (mean dose; $503.41 \mathrm{mg}$ ), ziprasidone (mean dose: $112.94 \mathrm{mg}$ ), aripiprazlole (mean dose: $21.85 \mathrm{mg}$ ), haloperidol (mean dose: 9.77 $\mathrm{mg})$, etc.

Clinicians were allowed to use their preference for medication switching strategies, including an abrupt switch, a taper switch, or a cross taper switch. Benzodiazepine, zolpidem, zopiclone, and beta blocker were permitted for the management of anxiety, insomnia, general behavior disturbances and/or extrapyramidal symptoms. Antidepressants (except MAOI) that had been taken for at least one month before study were permitted.

Patients were assigned into early response or early non-response groups at 4 weeks based on improvement in CGISCH-S score from baseline and CGI-SCH-I score at 4 weeks. We investigated 2 treatment responses rates based on 2 different response criteria such as CGI-I or CGI-S response criteria. These criteria were used already at other journal that evaluating the effectiveness of paliperidone ER. ${ }^{23}$ First, "CGI-I response criteria" was defined as a CGI-I score of 2 or lower at any visit. Second, "CGI-S response criteria" was defined as a reduction of 2 or higher from baseline (when baseline CGI $\geq 5$ ) or a reduction of 1 or higher from baseline (when baseline CGI-S=4).

\section{Data analysis}

\section{Baseline sociodemographic characteristics}

We obtained patients' sociodemographic informations, such as age, gender, schizophrenia type, educational status, occupational status, alcohol history, reason for medication change, main antipsychotics used before study, and mono- or poly-antipsychotic therapy.

\section{Clinical assessments}

To assess the clinical manifestations of patient, the following scales were utilized;

Krawiecka scale ${ }^{24}$ : The Krawiecka scale consists of eight items rated on a 5-point scale and is designed to measure psychopathology in patients with schizophrenia. Higher scores indicate more severe psychopathology. Subjective items "depressed", "anxious", "delusions", and "hallucinations" were assessed by pa- 
tients and objective items "incoherence", "poverty of speech", "flattened affect", and "psychomotor retardation" assessed by the clinicians.

Clinical Global Impression-Schizophrenia-Severity and -Improvement (CGI-SCH-S and CGI-SCH-I) ${ }^{25}$ : The CGI$\mathrm{SCH}$ was designed to evaluate the main symptom dimensions in patients with schizophrenia (positive, negative, depressive, cognitive).

Personal and social performance scale (PSS) ${ }^{26-28}$ : PSP included four specific domains of assessment (A- social useful activity including work and study; B- personal and social relationships; C- self-care; D- disturbing and aggressive behaviors). It is scored on a scale of 1 to 100 ; higher scores represent better psychosocial functioning.

Drug-induced Extrapyramidal Symptom Scale (DIEPSS) ${ }^{29}$ : The Drug-Induced Extrapyramidal Symptoms Scale (DIEPSS) was used to evaluate EPS. This instrument addresses eight specific symptoms (gait disturbances, bradykinesia, sialorrhea, musclerigidity, tremor, akathisia, dystonia, and dyskinesia) as well asglobal well-being.

And exams for height, weight, waist circumference, systolic blood pressure, diastolic blood pressure, blood laboratory factors (glucose, red blood cell counts, white blood cell counts, cholesterol, triglyceride, prolactin, etc) were performed at baseline and 4 weeks.

\section{Statistically methods}

The association of the selected variables with treatment response was assessed by comparing early responders and nonresponders with regard to the baseline values of the selected variables with the help of an independent t-test and a chi-square test for continuous and categorical data, respectively. Logistic regression was used to examine the effects of predictor variables on a dichotomous dependent variable (e.g., early response to paliperidone ER treatment). We employed SPSS version 18.0 for Windows for all statistical analyses and considered only pvalues less than 0.05 as statistically significant.

\section{RESULTS}

\section{Comparison of sociodemographic characteristics between early responders and non-responders}

In the entire multicenter study 685 patients were enrolled, 320 met inclusion criteria and they were examined in this analysis. 124 patients (38.7\%) were identified as treatment early responders, 196 (61.2\%) could not fulfill the early response criterion.

Sociodemographic characteristics of the early responders and non-responders groups are shown in Table 2. The early response group contained more patients with paranoid-type schizophrenia ( $78.2 \%$ vs. $60.2 \%, \mathrm{p}=0.006)$ and more patients who drink occasionally once a month (social drinkers) (33.9\% vs. $17.3 \%, \mathrm{p}=0.007)$. The non-response group contained a higher proportion of patients with undifferentiated-type schizophrenia and non-alcoholics. The early responders tended to start paliperidone at inpatient state, but non-responders contained a higher proportion of patients who started paliperidone at outpatient state. Regarding other variables (gender, age, age of onset, education history, occupation status, reason for medication change, antipsychotics and prescription pattern before screening, paliperidone starting dose), the differences between groups were not statistically significant.

\section{Comparison of baseline clinical data and subsequent response between early responders and non-responders}

We compared the baseline Krawiecka scale, CGI-SCH-S scale for evaluating the differences of psychopathology and PSP for social function, and DIEPSS for side effects (Table 3). Early responders scored lower on the items "flattened affect" and "psychomotor retardation" of Krawiecka scale. But there were no significant differences in other objective items "incoherence", "poverty of speech" and subjective items "depressed", "anxious", "delusions", "hallucinations" of Krawieka scale. In CGI-SCH-S, the early responders showed a significantly lower severity of the negative and cognitive symptomatology. Also, early responders were scored significantly lower on the PSP-A "social useful activity", B "personal and social relationship", and C "self-care". PSP-D "disturbing and aggressive behaviors" was not significantly different between groups. There were no significantly differences of side effects, as measured by the DIEPSS.

We compared the baseline metabolic parameters between early responders and non-responders. Early responders showed a significantly lower on the blood WBC counts $(6.52$ vs. 7.15, $\mathrm{p}=0.037$ ) (Table 4 ). With regard to all other variables, early responders and non-responders did not differ significantly.

After 24 weeks, $64.3 \%$ of responders at endpoint were correctly identified as early responders at 4 weeks (sensitivity) and $81.5 \%$ of non-responders were identified as non-responders at 4 weeks (sensitivity). $72.0 \%$ of early responders became responders at 24 weeks (positive predictive value, PPV) and $75.6 \%$ of early non-responders became non-responders at 24 weeks (negative predictive value, NPV).

\section{Results of multivariate logistic regression}

We next performed multivariate logistic regression using those variables that were found to differentiate between early responder and non-responders at a significant level of 0.05 . The variables included the schizophrenia type, state at medica- 
tion change, alcohol history, Krawiecka scale "flattened affect" and "psychomotor retardation", CGI-SCH-S score for negative and cognitive symptoms, and PSP-A, B, C. Of the variables, only CGI-SCH-S for negative symptoms, PSP-B, PSP-C, social drinks, and state at medication change were individually significant predictors of early responder/non-re-

Table 2. Baseline characteristics of patients: early response group vs. non-response group

\begin{tabular}{|c|c|c|c|}
\hline & Early response group $(\mathrm{N}=124)$ & Early non-response group $(\mathrm{N}=196)$ & p-value \\
\hline \multicolumn{4}{|l|}{ Sex, N (\%) } \\
\hline Male & $55(44.4)$ & $89(45.4)$ & \multirow[t]{2}{*}{0.854} \\
\hline Female & $69(55.6)$ & $107(54.6)$ & \\
\hline Age, mean $\pm S D$ & $36.94 \pm 10.66$ & $35.85 \pm 11.16$ & 0.384 \\
\hline Age of onset, mean $\pm \mathrm{SD}$ & $25.85 \pm 9.22$ & $26.59 \pm 8.94$ & 0.507 \\
\hline \multicolumn{4}{|l|}{ Schizophrenia type, N (\%) } \\
\hline Paranoid & $97(78.2)$ & $118(60.2)$ & \multirow{5}{*}{$0.006^{*}$} \\
\hline Disorganized & $1(0.8)$ & $9(4.6)$ & \\
\hline Catatonic & 0 & 0 & \\
\hline Residual & $3(2.4)$ & $8(4.1)$ & \\
\hline Undifferentiated & $23(18.5)$ & $61(31.1)$ & \\
\hline \multicolumn{4}{|l|}{ Alcohol history, N (\%) } \\
\hline None & $70(56.5)$ & $141(71.9)$ & \multirow{3}{*}{$0.007^{*}$} \\
\hline Social drinks (once a month) & $42(33.9)$ & $34(17.3)$ & \\
\hline Often ( $\geq 2$ a week) & $9(7.3)$ & $18(9.2)$ & \\
\hline \multicolumn{4}{|l|}{ Education history, N (\%) } \\
\hline$<7$ years & $12(9.7)$ & $8(4.1)$ & \multirow{4}{*}{0.160} \\
\hline $7-9$ years & $10(8.1)$ & $20(10.2)$ & \\
\hline $10-12$ years & $48(38.7)$ & $89(45.4)$ & \\
\hline$>12$ years & $54(43.5)$ & $79(40.3)$ & \\
\hline \multicolumn{4}{|l|}{ Occupation status, N (\%) } \\
\hline Unemployed & $102(82.3)$ & $166(84.7)$ & \multirow[t]{2}{*}{0.387} \\
\hline Employed & $22(17.7)$ & $28(14.3)$ & \\
\hline \multicolumn{4}{|l|}{ Reason for medication change } \\
\hline Lack of efficacy & $92(74.2)$ & $147(75.0)$ & \multirow{3}{*}{0.082} \\
\hline Lack of tolerance & $15(12.1)$ & $35(17.9)$ & \\
\hline Lack of compliance & $17(13.7)$ & $14(7.1)$ & \\
\hline \multicolumn{4}{|l|}{ State at medication change, $\mathrm{N}(\%)$} \\
\hline Inpatient & $51(41.1)$ & $50(25.5)$ & \multirow[t]{2}{*}{$0.003^{*}$} \\
\hline Outpatient & $73(58.9)$ & $146(74.5)$ & \\
\hline \multicolumn{4}{|l|}{ Antipsychotics before screening, N (\%) } \\
\hline Risperidone & $60(49.2)$ & $83(42.8)$ & \multirow{7}{*}{0.401} \\
\hline Olanzapine & $17(13.9)$ & $28(14.4)$ & \\
\hline Quetiapine & $4(3.3)$ & $9(4.6)$ & \\
\hline Ziprasidone & $3(2.5)$ & $12(6.2)$ & \\
\hline Aripirazole & $16(13.1)$ & $22(11.3)$ & \\
\hline Amilsulpiride & $8(6.6)$ & $19(9.8)$ & \\
\hline Typical & $11(9.0)$ & $22(11.3)$ & \\
\hline \multicolumn{4}{|l|}{ Prescription pattern before screening } \\
\hline Monotherapy & $101(81.5)$ & $151(77.0)$ & \multirow[t]{2}{*}{0.347} \\
\hline Polytherapy & $23(18.5)$ & $45(23.0)$ & \\
\hline Paliperidone starting dose, mean $\pm S D$ & $5.40 \pm 1.43$ & $5.58 \pm 1.67$ & 0.346 \\
\hline
\end{tabular}

Chi-square test was performed. Unpaired t-test was performed. ${ }^{*}$ p-value $<0.05$ statistically significant 
Table 3. Comparison of baseline psychiatric scales between early response and non-response group

\begin{tabular}{|c|c|c|c|}
\hline & Early response group $(\mathrm{N}=124)$ & Early non-response group $(\mathrm{N}=196)$ & p-value \\
\hline \multicolumn{4}{|l|}{ Krawiecka Scale (subjective) } \\
\hline Depressed & 1.56 & 1.58 & 0.922 \\
\hline Anxious & 1.80 & 1.77 & 0.781 \\
\hline Delusions & 2.35 & 2.45 & 0.500 \\
\hline Hallucinations & 1.93 & 2.03 & 0.562 \\
\hline \multicolumn{4}{|l|}{ Krawiecka Scale (objective) } \\
\hline Incoherence & 1.46 & 1.56 & 0.404 \\
\hline Poverty of speech & 1.15 & 1.33 & 0.141 \\
\hline Flattened affect & 1.64 & 1.92 & $0.014^{*}$ \\
\hline Psychomotor retardation & 1.31 & 1.58 & $0.024^{*}$ \\
\hline \multicolumn{4}{|l|}{ CGI-SCH-S (\%) } \\
\hline Positive & 2.94 & 3.08 & 0.339 \\
\hline Negative & 3.35 & 3.57 & $0.009^{*}$ \\
\hline Depressive & 2.94 & 3.08 & 0.320 \\
\hline Cognitive & 3.35 & 3.67 & $0.048^{*}$ \\
\hline \multicolumn{4}{|l|}{ Personal and Social Performance Scale } \\
\hline A (social useful activity) & 3.46 & 3.72 & $0.019^{*}$ \\
\hline B (personal and social relationship) & 3.48 & 3.80 & $0.002^{*}$ \\
\hline C (self-care) & 2.18 & 2.56 & $0.001^{*}$ \\
\hline D (disturbing and aggressive behaviors) & 1.96 & 1.88 & 0.472 \\
\hline DIEPSS & 3.41 & 4.13 & 0.151 \\
\hline
\end{tabular}

Unpaired t-test was performed. ${ }^{*}$ p-value $<0.05$ statistically significant. CGI-SCH-S: Clinical Global Impression-Schizophrenia-Severity, DIEPSS: drug-induced Extrapyramidal Symptom Scale

Table 4. Comparison of metabolic parameters between early response and non-response group

\begin{tabular}{lccc}
\hline & Early response group $(\mathrm{N}=124)$ & Early non-response group $(\mathrm{N}=196)$ & $\mathrm{p}$-value \\
\hline Body weight $(\mathrm{kg})$ & $63.57 \pm 13.26$ & $66.43 \pm 13.03$ & 0.059 \\
Waist circumstance $(\mathrm{cm})$ & $83.77 \pm 11.14$ & $86.17 \pm 10.96$ & 0.062 \\
Prolactin $(\mathrm{ng} / \mathrm{dL})$ & $47.99 \pm 55.19$ & $43.18 \pm 49.79$ & 0.628 \\
Total cholesterol (mg/dL) & $185.52 \pm 39.74$ & $183.98 \pm 38.91$ & 0.989 \\
Triglyceride (mg/dL) & $140.87 \pm 90.65$ & $143.95 \pm 95.48$ & 0.826 \\
High density lipoprotein (mg/dL) & $48.84 \pm 11.58$ & $47.44 \pm 13.79$ & 0.452 \\
Glucose (mg/dL) & $102.74 \pm 34.57$ & $103.41 \pm 31.09$ & 0.901 \\
WBC (mg/dL) & $6.52 \pm 1.86$ & $7.15 \pm 2.18$ & $0.037^{*}$ \\
\hline
\end{tabular}

Unpaired t-test was performed. ${ }^{*}$ p-value $<0.05$ statistically significant. WBC: white blood cell

sponder status $(\mathrm{p}<0.05)$ (Table 5). The CGI-SCH-S for negative symptoms and PSP-B, C had an Exp (B) that was significantly greater than 1.0, indicating that the scores were higher for the non-responders group, whereas the other 2 had an $\operatorname{Exp}(\mathrm{B})$ that were significantly less than 1.0 indicating that among non-responders there were less social drinkers and patients who started at inpatient state.

\section{DISCUSSION}

In this study, we assessed the clinical response of patients who changed the medication to paliperidone ER. The early response rate based on CGI-S and CGI-I criteria was 38.7\%. Our early response rate (38.7\% of patients) is some different compared to those reported by other studies. For example, Kinon et al. ${ }^{15}$ evaluated early response in 1077 patients using the definition as $\geq 20 \%$ PANSS total score improvement at week 2 and identified $30 \%$ of the patients to become early responders. Also, applying the $20 \%$ psychopathological improvement as early response definition, Chang et al. ${ }^{30}$ reported of $30 \%$ of schizophrenia patients to achieve early response in their study. Recently, Schennach et al. ${ }^{31}$ examined 370 patients and found $46 \%$ of them to fulfill their early response criterion which was defined as $\mathrm{a} \geq 30 \%$ PANSS total score reduction within the first two weeks.

The differences of results could be attributed to different 
Table 5. Results of logistic regression analysis of selected variables distinguishing early responders from non-responders

\begin{tabular}{|c|c|c|c|c|c|c|}
\hline & $\mathrm{B}$ & S.E. & Wald & $\operatorname{Exp}(B)$ & $95 \% \mathrm{CI}$ & p-value \\
\hline Subtype of schizophrenia (paranoid) & -0.536 & 0.286 & 3.646 & 0.585 & $0.334-1.026$ & 0.061 \\
\hline Social drinkers (sonce a month) & -0.767 & 0.286 & 7.197 & 0.465 & $0.265-0.813$ & $0.007^{*}$ \\
\hline Starting at inpatient & -1.051 & 0.276 & 14.529 & 0.350 & $0.204-0.600$ & $<0.001^{*}$ \\
\hline Krawiecka Scale item (flattened affect) & 0.194 & 0.139 & 1.951 & 1.214 & $0.925-1.592$ & 0.162 \\
\hline Krawiecka Scale item (psychomotor retardation) & 0.150 & 0.138 & 1.167 & 1.162 & $0.885-1.526$ & 0.280 \\
\hline CGI-S-N & 0.269 & 0.107 & 6.359 & 1.309 & $1.062-1.613$ & $0.012^{*}$ \\
\hline CGI-S-C & 0.090 & 0.116 & 0.611 & 1.095 & $0.873-1.373$ & 0.435 \\
\hline PSP-A & 0.012 & 0.203 & 0.010 & 1.001 & $0.673-1.489$ & 0.897 \\
\hline PSP-B & 0.355 & 0.159 & 5.025 & 1.427 & $1.046-1.946$ & $0.025^{*}$ \\
\hline PSP-C & 0.337 & 0.139 & 5.845 & 1.400 & $1.066-1.839$ & $0.016^{*}$ \\
\hline
\end{tabular}

${ }^{*}$ p-value $<0.05$ statistically significant. CGI: Clinical Global Impression, PSP-A: Personal and Social Performance Scale-social useful activity including work and study, PSP-B: Personal and Social Performance Scale-personal and social relationships, PSP-C: Personal and Social Performance Scale-self-care, CI: confidence interval

study designs. Other studies included the subjects who treated with various antipsychotic agents. But we evaluated the patients who required a change antipsychotic medication to paliperdione ER because of low efficacy, low tolerance, or low compliance. And patients were moderately ill at baseline defined by the 4 or higher on the CGI-S scale at screening. However, these different results might also partly reflect the heterogeneous course of antipsychotic response in schizophrenia. There have been some studies about the heterogeneity of response to treatment in schizophrenia. ${ }^{32-34}$ Recently, Schennach et al. ${ }^{34}$ investigated the 399 patients and identified five distinct response trajectories based on the patients' changes in the PANSS total score. They found that $15 \%$ of the patients to feature a early and considerable improvement. Stauffer et al. ${ }^{32}$ evaluated 6 double-blind, randomized clinical trials and suggested five distinct response trajectories. In this study, $2.4 \%$ of patients showed rapid and dramatic response who achieved a $51 \%$ reduction in mean PANSS total score by week 3 . These features may be genetically determined, with some combination of receptor polymorphisms increasing the likelihood of a good treatment response. ${ }^{35}$ Therefore, schizophrenia is thought to be heterogeneous disorder, more studies about response trajectories are necessary for optimizing treatment strategies.

Early responders and non-responders were distinguished from one another on several sociodemographic and clinical characteristics. In this study, there were more social drinkers who drink once a month in early responder. Although non-responders contained more patients who did not drink, there were more heavy drinkers in non-responder groups. Generally, alcohol consumption is thought to be harmful to the schizophrenic patients. ${ }^{36-38}$ Alcohol abuse and dependence have been reported to exacerbate the clinical course of schizophrenia. However, a little alcohol use might help the patients reduce the anxiety, agitation and insomnia. Also, in society of Korea, so- cial drinks might help the patients make the relationships with their family and friends. The findings that non-alcoholics were more in non-responder groups might indicate their poorer function of social relationships. We found a significant difference between inpatient and outpatients in their likelihood to respond to the paliperidone ER treatment. The patients who changed the medication at inpatient state had a more favorable response than those at outpatient state. This result could be attributed to several factors, including more systemic switching schedule, careful administration of drug intake, frequent meeting with clinicians, and close observations by clinicians. Also, the patients could get a more detailed education about the medications by their doctors and have a positive attitude to paliperidone ER. Therefore, if possible, we recommended the hospitalization for a short time during switching to paliperidone ER. There were significant differences in the type of schizophrenia between early responder and non-responders. Non-responders had relatively more patients with undifferentiated type of schizophrenia. The reason behind this difference may be the type difference in the prognosis of schizophrenia. Generally, paranoid type is thought to have better course than other type, there might be relatively more patients in early responder groups.

In terms of psychopathology, the non-responder showed poorer functioning in the item "fattened affect" and "psychomotor retardation" of Krawiecka scale. In multivariate logistic analysis, the severity of negative symptoms at baseline was independently associated with a less likely response to paliperidone ER. In past some studies, severity of general psychopathology and positive symptoms at baseline had predictive value for early response. ${ }^{18,39,40}$ For example, in a study by Palao et al., ${ }^{39}$ the degree of positive symptoms exclusively predicted better response to treatment when potential sociodemographic and clinical influencing factors were examined. Crespo- 
Facorro et al. ${ }^{18}$ examined 172 first-episode patients and identified that the severity of positive symptoms at baseline predicted better clinical response. However, it is commonly accepted that the presence and severity of negative symptoms are associated with poor outcome in schizophrenia ${ }^{41-43}$ In our study, patients not achieving response were mainly hindered from becoming treatment responders by the negative symptoms. Our result may indicate that, although paliperidone ER is new second generation antipsychotic agent, it is relatively less effective for the negative symptom than for the positive symptom. Of the negative symptoms, especially, clinicians should care about patients' affective disturbance and psychomotor retardation. Also, for early response, clinicians need to consider additional and specific treatment approaches and strategies to reduce the burden of negative symptom.

Furthermore, previous studies have found an association between a poor premorbid functioning and a lower response to treatment. ${ }^{44-48}$ In our studies, we investigated patients' social function by PSP four categories scale and compared between early responders and non-responder. Non-responders were scored significantly higher on the PSP-A "social useful activity", B "personal and social relationship", and C "self-care". In multivariate logistic regression model, only higher baseline PSP-B and C score predicted a less likelihood of responding to paliperidone ER. This result underlines the impact of social relationship and self-care for treatment response. Today the goal of treatment for schizophrenia is not just improving positive and negative symptoms. In other words, improvement of realworld functioning is more important for schizophrenic patients. Furthermore, our results support that improvement of social relationships and self-care eventually could help to achieve early response for medication. Therefore, in addition to drug prescriptions, we suggest that clinicians should establish the treatment strategies to improve patients' social relationships and self-care, such as cognitive behavior treatment, group psychotherapy and social skill training.

Interestingly, in metabolic parameters, non-responders showed a significant higher white blood cell counts (6.52 vs. $7.15, \mathrm{p}=0.037)$. There have been a few studies about the biological markers of early responders. Some studies suggested the association of schizophrenia and inflammation. ${ }^{49-51}$ In a study of Fan et al. higher white blood cell counts are associated with more severe psychopathology in non-diabetic schizophrenia. ${ }^{50}$ However, it is uncertain whether WBC counts could have predictive value for the response. Future research about the underlying biological mechanisms and genetic underpinnings of rapid and favorable responders is needed.

This study had some limitations. First, our study was openlabel and non-comparative, reflecting treatment in real-world settings, where patient control and monitoring may be less than found in a randomized, controlled trial. And paliperidone ER was up- and down-titrated (3-12 mg) during the study on the clinicians' decision. The role of dose and titration in the early response needs further study. Second, the short time of follow up of the present analysis (first 4 weeks) hinders exploring and comparing the predictive values of these variables in long-term outcomes. Third, we collected the data from the patients who were moderately ill and needed to change the medication, so, these results' generalizability for all schizophrenic patients may be limited. However, there has been little known about the early responder to paliperidone ER treatment. Forth, we analyzed the subjects who completed the studies for 24 weeks. Therefore, the effect of dropout patients was not considered. Further studies about effectiveness and adherence are needed in the future. Lastly, we evaluated clinical response using the CGI scale. But, generally, it would be recommended to use BPRS or PANSS change from baseline to assess the rate of clinical response. This drawback clearly limits the replicability and comparability of our findings. And the rate of response according to CGI scale was relatively low. This might be because the subjects of our study were the patients switched from other antipsychotics, not drug naïe patients.

And, our studies compared the detailed sociodemographic and clinical characteristics between early responder and nonresponder. Additionally, we compared the baseline social functioning and laboratory data. Therefore, our results may become the basis for future studies.

In conclusion, our results suggest that patients with a lower severity of negative symptoms and good social relationships and appropriate self-care seem may have a increase likelihood of early responding to paliperidone ER. For the early response, clinicians should pay more attention to these aspects and consider the additional strategies to improve these symptoms. Also, identifying those patients with a decrease likelihood of responding to treatment may help clinicians to optimizing therapeutic effort to benefit individuals.

\section{REFERENCES}

1. Wu EQ, Birnbaum HG, Shi L, Ball DE, Kessler RC, Moulis M, et al. The economic burden of schizophrenia in the United States in 2002. J Clin Psychiatry 2005;66:1122-1129.

2. Hong J, Windmeijer F, Novick D, Haro JM, Brown J. The cost of relapse in patients with schizophrenia in the European SOHO (Schizophrenia Outpatient Health Outcomes) study. Prog Neuropsychopharmacol Bio Psychiatry 2009;33:835-841.

3. Marder SR, Kramer M, Ford L, Eerdekens E, Lim P, Eerdekens M, et al. Efficacy and safety of paliperidone extended-release tablets: results of a 6-week, randomized, placebo-controlled study. Biol Psychiatry 2007;62:1363-1370.

4. Kane J, Canas F, Kramer M, Ford L, Gassmann-Mayer C, Lim P, et al. Treatment of schizophrenia with paliperidone extended-release tablets: a 6-week placebo-controlled trial. Schizophr Res 2007;90:147-161. 5. Davidson M, Emsley R, Kramer M, Ford L, Pan G, Lim P, et al. Effica- 
cy, safety and early response of paliperidone extended-release tablets (paliperidone ER): results of a 6-week, randomized, placebo-controlled study. Schizophr Res 2007;93:117-130.

6. Meltzer HY, Bobo WV, Nuamah IF, Lane R, Hough D, Kramer M, et al. Efficacy and tolerability of oral paliperidone extended-release tablets in the treatment of acute schizophrenia: pooled data from three 6-week, placebo-controlled studies. J Clin Psychiatry 2008;69:817-829.

7. Emsley R, Berwaerts J, Eerdekens M, Kramer M, Lane R, Lim P, et al. Efficacy and safety of oral paliperidone extended-release tablets in the treatment of acute schizophrenia: pooled data from three 52-week open-label studies. Int Clin Psychopharmacol 2008;23:343-356.

8. Canuso CM, Youssef EA, Bossie CA, Turkoz I, Schreiner A, Simpson GM. Paliperidone extended-release tablets in schizophrenia patients previously treated with risperidone. Int Clin Psychopharmacol 2008; 23:209-215.

9. Chwieduk CM, Keating GM. Paliperidone extended release: a review of its use in the management of schizophrenia. Drugs 2010;70:12951317.

10. Citrome L. Oral paliperidone extended-release: chemistry, pharmacodynamics, pharmacokinetics and metabolism, clinical efficacy, safety and tolerability. Expert Opin Drug Metab Toxicol 2012;8:873-888.

11. Vermeir M, Naessens I, Remmerie B, Mannens G, Hendrickx J, Sterkens $\mathrm{P}$, et al. Absorption, metabolism, and excretion of paliperidone, a new monoaminergic antagonist, in humans. Drug Metab Dispos 2008; 36:769-779.

12. Stern RG, Kahn RS, Davidson M. Predictors of response to neuroleptic treatment in schizophrenia. Psychiatr Clin North Am 1993;16:313338

13. Correll CU, Malhotra AK, Kaushik S, McMeniman M, Kane JM. Early prediction of antipsychotic response in schizophrenia. Am J Psychiatry 2003;160:2063-2065.

14. Emsley R, Oosthuizen PP, Kidd M, Koen L, Niehaus DJ, Turner HJ. Remission in first-episode psychosis: predictor variables and symptom improvement patterns. J Clin Psychiatry 2006;67:1707-1712.

15. Kinon BJ, Chen L, Ascher-Svanum H, Stauffer VL, Kollack-Walker S, Sniadecki JL, et al. Predicting response to atypical antipsychotics based on early response in the treatment of schizophrenia. Schizophr Res 2008; 102:230-240.

16. Kinon BJ, Chen L, Ascher-Svanum H, Stauffer VL, Kollack-Walker S, Zhou W, et al. Early response to antipsychotic drug therapy as clinical marker of subsequent response in the treatment of schizophrenia. Neuropsychopharmacology 2010;35:581-590.

17. Lin CH, Chou LS, Lin CH, Hsu CY, Chen YS, Lane HY. Early prediction of clinical response in schizophrenia patients receiving the atypical antipsychotic zotepine. J Clin Psychiatry 2007;68:1522-1527.

18. Crespo-Facorro B, Pelayo-Terán JM, Pérez-Iglesias R, Ramírez-Bonilla M, Martínez-García O, Pardo-García G, et al. Predictors of acute treatment response in patients with a first episode of non-affective psychosis: sociodemographics, premorbid and clinical variables. J Psychiatr Res 2007;41:659-666.

19. Levine SZ, Leucht S. Elaboration on the early-onset hypothesis of antipsychotic drug action: treatment response trajectories. Biol Psychiatry 2010;68:86-92.

20. Hatta K, Nakamura H, Matsuzaki I. Acute-phase treatment in general hospitals: clinical psychopharmacologic evaluation in first-episode schizophrenia patients. Gen Hosp Psychiatry 2003;25:39-45.

21. Kim SW, Yoon JS, Kim YS, Ahn YM, Kim CE, Go HJ, et al. The effect of paliperidone extended release on subjective well-being and responses in patients with schizophrenia. Prog Neuropsychopharmacol Biol Psychiatry 2012;38:228-235.

22. Moon YS, Na KS, Kim CE, Kim YS, Yoon JS, Ahn YM, et al. Efficacy and safety of paliperidone extended release in schizophrenia patients requiring a switch in antipsychotic medication by switching previous antipsychotics to paliperidone extended release. Korean J Psychopharmacology 2012;23:97-106.
23. Lee JS, Ahn JH, Lee JI, Kim JH, Jung I, Lee CU, et al. Dose pattern and effectiveness of paliperidone extended-release tablets in patients With schizophrenia. Clin Neuropharmacol 2011;34:186-190.

24. Krawiecka M, Goldberg D, Vaughan M. A standardized psychiatric assessment scale for rating chronic psychotic patients. Acta Psychiatr Scand 1977;55:299-308.

25. Haro JM, Kamath SA, Ochoa S, Novick D, Rele K, Fargas A, et al. The Clinical Global Impression-Schizophrenia scale: a simple instrument to measure the diversity of symptoms present in schizophrenia. Acta Psychiatr Scand Suppl 2003;(416):16-23.

26. Morosini PL, Magliano L, Brambilla L, Ugolini S, Pioli R. Development, reliability and acceptability of a new version of the DSM-IV Social and Occupational Functioning Assessment Scale (SOFAS) to assess routine social functioning. Acta Psychiatr Scand 2000;101:323329 .

27. Lee JG, Seok JH, Lee JY, Lee KU, Kwak KH, Kwon JS, et al. A validation study of the Korean-version of the personal and social performance scale. Korean J Psychopharmacol 2006;17:497-506.

28. Patrick DL, Burns T, Morosini P, Rothman M, Gagnon DD, Wild D, et al. Reliability, validity and ability to detect change of the clinician-rated personal and social performance scale in patients with acute symptoms of schizophrenia. Curr Med Res Opin 2009;25:325-338.

29. Inada T, Yagi G, Miura S. Extrapyramidal symptom profiles in Japanese patients with schizophrenia treated with olanzapine or haloperidol. Schizophr Res 2002;57:227-238.

30. Chang YC, Lane HY, Yang KH, Huang CL. Optimizing early prediction for antipsychotic response in schizophrenia. J Clin Psychopharmacol 2006;26:554-559.

31. Schennach-Wolff R, Meyer S, Seemüller F, Jäger M, Schmauss M, Laux $\mathrm{G}$, et al. Influencing factors and predictors of early improvement in the acute treatment of schizophrenia and schizophrenia spectrum disorder. J Psychiatr Res 2011;45:1639-1647.

32. Stauffer V, Case M, Kollack-Walker S, Ascher-Svanum H, Ball T, Kapur S, Kinon BJ. Trajectories of response to treatment with atypical antipsychotic medication in patients with schizophrenia pooled from 6 double-blind, randomized clinical trials. Schizophr Res 2011;130:1119.

33. Levine SZ, Rabinowitz J, Faries D, Lawson AH, Ascher-Svanum H. Treatment response trajectories and antipsychotic medications: examination of up to 18 months of treatment in the CATIE chronic schizophrenia trial. Schizophr Res 2012;137:141-146.

34. Schennach R, Meyer S, Seemüller F, Jäger M, Schmauss M, Laux G, et al. Response trajectories in "real-world" naturalistically treated schizophrenia patients. Schizophr Res 2012;139:218-224.

35. Collier DA. Pharmacogenetics in psychosis. Drug News Perspect 2003; 16:159-165.

36. Räsänen P, Tiihonen J, Isohanni M, Rantakallio P, Lehtonen J, Moring J. Schizophrenia, alcohol abuse, and violent behavior: a 26-year followup study of an unselected birth cohort. Schizophr Bull 1998;24:437441.

37. Fazel S, Långström N, Hjern A, Grann M, Lichtenstein P. Schizophrenia, substance abuse, and violent crime. JAMA 2009;301:2016-2023.

38. Jones RM, Lichtenstein P, Grann M, Långström N, Fazel S. Alcohol use disorders in schizophrenia: a national cohort study of 12,653 patients. J Clin Psychiatry 2011;72:775-779.

39. Palao DJ, Arauxo A, Brunet M, Marquez M, Bernardo M, Ferrer J, et al. Positive versus negative symptoms in schizophrenia: response to haloperidol. Prog Neuropsychopharmacol Biol Psychiatry 1994;18: 155-164.

40. Robinson DG, Woerner MG, Alvir JMJ, Geisler S, Koreen A, Sheitman B, et al. Predictors of treatment response from the first episode of schizophrenia or schizoaffective disorder. Am J Psychiatry 1999;156: 544-549.

41. Breier A, Schreiber JL, Dyer J, Pickar D. National Institute of Mental Health longitudinal study of chronic schizophrenia. Prognosis and 
predictors of outcome. Arch Gen Psychiatry 1991;48:239-246.

42. Fenton WS, McGlashan TH. Natural history of schizophrenia subtypes. II. Positive and negative symptoms and long-term course. Arch Gen Psychiatry 1991;48:978-86.

43. Mayerhoff DI, Loebel AD, Alvir JML, Szymanski SR, Geisler SH, Borenstein $\mathrm{M}$, et al. The deficit state in first-episode schizophrenia. Am J Psychiatry 1994;151:1417-1422.

44. McGlashan TH. The prediction of outcome in chronic schizophrenia. IV. The Chestnut Lodge follow-up study. Arch Gen Psychiatry 1986; 43:167-176.

45. Johnstone EC, Macmillian JF, Frith CD, Benn DK, Crow TJ. Further investigation of the predictors of outcome following first schizophrenic episodes. Br J Psychiatry 1990;157:182-189.

46. Ammimger GP, Resch F, Mutschlechner R, Friedrich MH, Ernst E. Premorbid adjustment and remission of positive symptoms in first-episode of psychosis. Eur Child Adolesc Psychiatry 1997;6:212-218.

47. Larsen TK, Moe LC, Vibe-Hansen L, Johannessen JO. Premorbid functioning versus duration of untreated psychosis in 1 year outcome in first-episode psychosis. Schizophr Res 2000;45:1-9.
48. Perkins D, Lieberman J, Gu H, Tohen M, McEvoy J, Green A, et al. Predictors of antipsychotic treatment response in patients with firstepisode schizophrenia, schizoaffective and schizophreniform disorders. Br J Psychiatry 2004;185:18-24.

49. Muller N, Schwarz M. Schizophrenia as an inflammation-mediated dysbalance of glutamatergic neurotransmission. Neurotox Res 2006; 10:131-148.

50. Fan X, Liu EY, Freudenreich O, Park JH, Liu D, Wang J, et al. Higher white blood cell counts are associated with an increased risk for metabolic syndrome and more severe psychopathology in non-diabetic patients with schizophrenia. Schizophr Res 2010;118:211-217.

51. Benros ME, Nielsen PR, Nordentoft M, Eaton WW, Dalton SO, Mortensen PB. Autoimmune diseases and severe infections as risk factors for schizophrenia: a 30-year population-based register study. Am J Psychiatry 2011;168:1303-1310.

52. Schennach R, Jäger M, Mayr A, Meyer S, Kühn KU, Klingberg S, et al. Predictors of response and remission in the acute treatment of firstepisode schizophrenia patients--is it all about early response? Eur Neuropsychopharmacol 2011;21:370-378. 